\title{
An extract of Polygonum multiflorum protects against free radical damage induced by ultraviolet $B$ irradiation of the skin
}

I.K. Hwang ${ }^{1,2}$, K.-Y. Yoo ${ }^{2}$, D.W. Kim ${ }^{1}$, S.J. Jeong ${ }^{1}$, C.-K. Won ${ }^{3}$, W.-K. Moon ${ }^{1}$, Y.S. Kim ${ }^{4}$, D.Y. Kwon ${ }^{5}$, M.H. Won ${ }^{2}$ and D.-W. Kim ${ }^{1}$

\author{
${ }^{1}$ Central Research Center, Natural F\&P Co., Ltd., Chunchon, South Korea \\ ${ }^{2}$ Department of Anatomy, College of Medicine, Hallym University, Chunchon, South \\ Korea \\ ${ }^{3}$ Department of Anatomy, College of Veterinary Medicine and Institute of Animal \\ Science, Gyeongsang National University, Jinju, South Korea \\ ${ }^{4}$ Medical Science Division, Korea Research Institute of Chemical Technology, \\ Daejeon, South Korea \\ ${ }^{5}$ Korea Food Research Institute, Kyongki-do, South Korea
}

\section{Correspondence}

D.-W. Kim

Central Research Center

Natural F\&P Co., Ltd.

198-60 Hupyung-Dong

Chunchon 200-163

South Korea

Fax: +82-33-258-6773

E-mail: drkimdw@hanmail.net

Research supported by the BioFoods Project in Korea

Nano/Bio Plan under Ministry of Science and Technology of Korea.

Received July 18, 2005 Accepted August 10, 2006

\begin{abstract}
Over the last decades, the incidence of ultraviolet B (UVB)-related skin problems has been increasing. Damages induced by UVB radiation are related to mutations that occur as a result of direct DNA damage and/or the production of reactive oxygen species. We investigated the anti-oxidant effects of a Polygonum multiflorum thumb extract against skin damage induced by UVB irradiation. Female SKH-1 hairless mice were divided into three groups: control $(\mathrm{N}=7)$, distilled water- $(\mathrm{N}=10)$, and $P$. multiflorum extract-treated (PM, $\mathrm{N}=$ 10) groups. The PM (10 g) was extracted with $100 \mathrm{~mL}$ distilled water, cryo-dried and $9.8 \mathrm{~g}$ was obtained. The animals received a topical application of $500 \mu \mathrm{L}$ distilled water or PM extract $(1,2,4,8$, and $16 \%$, $\mathrm{w} / \mathrm{v}$, dissolved in distilled water) for $30 \mathrm{~min}$ after UVB irradiation (wavelength $280-320 \mathrm{~nm}, 300 \mathrm{~mJ} / \mathrm{cm}^{2} ; 3 \mathrm{~min}$ ) of the dorsal kin for 14 days, and skin immunohistochemistry and $\mathrm{Cu}, \mathrm{Zn}$-superoxide dismutase (SOD1) activity were determined. SOD1 immunoreactivity, its protein levels and activities in the skin were significantly reduced by $70 \%$ in the distilled water-treated group after UVB irradiation compared to control. However, in the PM extract-treated groups, SOD1 immunoreactivity and its protein and activity levels increased in a dose-dependent manner (1-16\%, w/v, PM extract) compared to the distilled water-treated group. SOD1 protein levels and activities in the groups treated with 8 and 16\%,w/v, PM extract recovered to $80-90 \%$ of the control group levels after UVB. These results suggest that PM extract strongly inhibits the destruction of SOD1 by UV radiation and probably contains anti-skin photoaging agents.
\end{abstract}

Key words

- Polygonum multiflorum extract

- Skin

- Ultraviolet B irradiation

- Free radicals

- Cu,Zn-superoxide

dismutase

- Hairless mouse 


\section{Introduction}

It is generally accepted that air pollution is reducing the ozone layer, a phenomenon predicted to increase the levels of ultraviolet (UV) radiation reaching the earth's surface. The incidence of ultraviolet B (UVB)-related skin problems and the interest in protecting the skin from the harmful effects of UVB are increasing (1-3). Although UVB represents only a small part of the UV spectrum, it has potent biological effects in terms of skin cancer (4), skin aging (5) and cataract formation $(6,7)$. The damages induced by UVB radiation are mediated by a complex cascade of events initiated by chromosomal alterations and mutations that occur as a result of direct DNA damage and/or the production of reactive oxygen species (810). Moreover, UVB-induced free radical formation and subsequent lipid peroxidation are considered to be a major mechanism of UV irradiation-induced cutaneous photodamage (11).

Some herbs used in traditional Oriental medicine have potent anti-oxidative effects against UVB-induced skin damage, ischemic brain damage, and free radical damage (3, 12). The root of Polygonum multiflorum thumb (PM) is used in Oriental medicine because it is said to have mild antibacterial and antifungal effects, and an anti-aging effect (13). In addition, it has been reported that PM extracts promote cellular antioxidant activity, increase the activity of $\mathrm{Cu}, \mathrm{Zn}$ superoxide dismutase (SOD1), inhibit the formation of oxidized lipids, and repress lipid peroxidation in the mitochondria of the rat heart (14).

Although PM has been found to act as an anti-oxidant in rat heart disease (14), no studies have been undertaken on its protective effects against UVB-induced skin damage. In the present study, we determined the anti-oxidant effects of PM topically applied to UVB-irradiated skin in hairless mice.

\section{Material and Methods}

\section{Experimental animals}

The progeny of female SKH-1 hairless mice ( 8 weeks old) obtained from Charles River Laboratories (Wilmington, MA, USA) were allowed to acclimatize for 7 days prior to the beginning of the experiment. The animals were housed under constant temperature $\left(23^{\circ} \mathrm{C}\right)$ and relative humidity $(60 \%)$ with a 12-h light/dark cycle and free access to food and water. Procedures involving animals and their care conformed to the institutional guidelines, which are in compliance with current international laws and policies of NIH 1996 (15) and were approved by the Institutional Animal Care and Use Committee of the Hallym Medical Center. All experiments were conducted to minimize the number of animals used and the suffering caused.

\section{Extraction of Polygonum multiflorum}

Dry PM roots were purchased from a local store in South Korea and extracted as described in a previous study (16). Briefly, dried PM roots were cut into small pieces and extracted three times with distilled water, and the extracts were concentrated by evaporation.

\section{Treatment with Polygonum multiflorum extract}

The animals were divided into three groups. The first group served as control. The second group received a topical application of $500 \mu \mathrm{L}$ distilled water on the dorsal skin after UVB irradiation $\left(300 \mathrm{~mJ} / \mathrm{cm}^{2} ; 3\right.$ min) daily for 14 days. The third groups received a topical application of $500 \mu \mathrm{L}$ of the PM extract $(1,2,4,8$, and $16 \%$, w/v, in distilled water, respectively) daily for 14 days on the dorsal skin immediately after UVB irradiation (wavelength $280-320 \mathrm{~nm}$, 
$300 \mathrm{~mJ} / \mathrm{cm}^{2} ; 3 \mathrm{~min}$ ) (17). The animals were anesthetized with a mixture of $2.5 \%$ isoflurane (Baxtor, Deerfield, IL, USA) in 33\% oxygen and $67 \%$ nitrous oxide during the topical application of distilled water or PM extract.

\section{Tissue processing}

The dorsal skins of the control, distilled water- and PM extract-treated animals were processed simultaneously at the same time on the same day. For immunohistochemistry, the animals were anesthetized with pentobarbital sodium, and then affected areas were dissected out and fixed with paraformaldehyde in $100 \mathrm{mM}$ PBS for $6 \mathrm{~h}$. The tissues were cryoprotected by infiltration with $30 \%$ sucrose overnight and then frozen and serially sectioned into $10-\mu \mathrm{m}$ thick vertical sections on a cryostat, and the sections were mounted onto gelatin-coated glass slides.

\section{SOD1 immunohistochemistry}

The sections of the control $(\mathrm{N}=7)$, distilled water- and PM extract-treated groups $(\mathrm{N}=10$ in each group) were processed simultaneously for immunohistochemistry at the same time on the same day. The sections were sequentially treated with $0.3 \%$ hydrogen peroxide in PBS for $30 \mathrm{~min}$ and $10 \%$ normal horse serum in $50 \mathrm{mM}$ PBS for 30 $\min$. They were next incubated with diluted sheep anti-SOD1 antibody (diluted 1:1,000, Calbiochem, San Diego, CA, USA) overnight at room temperature and subsequently exposed to biotinylated rat anti-sheep $\mathrm{IgG}$ and streptavidin peroxidase complex (1:200, Vector Laboratories, Burlingame, CA, USA). Next, the immunoreactive cells were visualized with 3,3'-diaminobenzidine in $0.1 \mathrm{M}$ Tris buffer, dehydrated and mounted with Canada Balsam (Kanto, Tokyo, Japan) (18).

In order to establish the specificity of immunostaining, a negative control was car- ried out by substituting normal sheep serum for primary antibody or by omitting the primary antibody. The negative control indicated the absence of immunoreactivity in the cell structures.

\section{Western blot analysis}

Seven animals in each group were used for the Western blot study (19). After sacrifice, the areas or irradiated skin were removed and the tissues were homogenized in $50 \mathrm{mM}$ PBS, pH 7.4, containing $0.1 \mathrm{mM}$ EGTA, pH 8.0, 0.2\% NP-40, 10 mM EDTA, pH 8.0, $15 \mathrm{mM}$ sodium pyrophosphate, 100 $\mathrm{mM}$ ß-glycerophosphate, $50 \mathrm{mM} \mathrm{NaF}, 150$ $\mathrm{mM} \mathrm{NaCl}, 2 \mathrm{mM}$ sodium orthovanadate, 1 $\mathrm{mM}$ PMSF, and $1 \mathrm{mM}$ DTT. After centrifugation at $10,000 \mathrm{~g}$, protein concentration was determined in the supernatants using the Micro BCA protein assay kit with bovine serum albumin as the standard (Pierce Chemical Company, Rockford, IL, USA).

Aliquots containing $20 \mu \mathrm{g}$ total protein were boiled in loading buffer containing 150 $\mathrm{mM}$ Tris, $\mathrm{pH}$ 6.8, 3 mM DTT, 6\% SDS, $0.3 \%$ bromophenol blue, and $30 \%$ glycerol. Then, each aliquot was loaded onto a $10 \%$ polyacrylamide gel. After electrophoresis, the gels were transferred to nitrocellulose membranes (Schleicher and Schuell, Keene, $\mathrm{NH}$, USA). To reduce background staining, the membranes were incubated with $5 \%$ nonfat dry milk in PBS containing $0.1 \%$ Tween 20 for $45 \mathrm{~min}$, followed by incubation with sheep anti-SOD1 antiserum $(1: 1,000)$ containing peroxidase conjugated rabbit antisheep IgG (Sigma, St. Louis, MO, USA), and then with an ECL kit (Amersham, Buckinghamshire, UK).

\section{Determination of SOD1 activity}

The same animals used for Western blot analysis were used in this analysis. SOD1 activity in the skin was measured according to a previous study $(18,19)$. The assay mix- 
ture consisted of a $2.90-\mathrm{mL}$ solution (solution A) containing $6.2 \mathrm{mg}$ xanthine and 65.4 mg cytochrome $\mathrm{C}$ in $0.05 \mathrm{M} \mathrm{KH}_{2} \mathrm{PO}_{4} / \mathrm{NaOH}$ buffer, $\mathrm{pH} 7.8$, and $50 \mu \mathrm{L}$ enzyme. Prior to addition of the enzyme, the absorbance of solution A at $550 \mathrm{~nm}$ was monitored for 2.0 min at 30-s intervals to establish a baseline slope. The extract used in the Western blot $(50 \mu \mathrm{L})$ was then added to solution A and absorbance measurement was continued every $30 \mathrm{~s}$ for another $4.0 \mathrm{~min}$. The slope ( $\Delta \mathrm{Abs} / \Delta \mathrm{t}$ ) observed from 2.5 to $5.5 \mathrm{~min}$ was then compared to the slope during the first $2.0 \mathrm{~min}$ to determine if the test solution reduced the rate of cytochrome $\mathrm{C}$ reduction (increase in absorbance at $550 \mathrm{~nm}\left(\mathrm{~A}_{550}\right)$ ). Each sample was assayed at least twice, unless otherwise noted.

One unit of SOD1 activity was defined as a $50 \%$ decrease in the rate of cytochrome $\mathrm{C}$ reduction. Ideally, the initial rate of cytochrome $\mathrm{C}$ reduction after SOD1 addition was a change of 0.025 absorbance units per minute at $550 \mathrm{~nm}$. To calculate the units of SOD1 activity in the assayed fraction, the rate of $\mathrm{A}_{550}$ increase from 2.5 to $5.5 \mathrm{~min}$ was divided by the initial rate from 0 to $2.0 \mathrm{~min}$. This represents the percent difference in rate $(18,19)$. This was subtracted from $100 \%$ to obtain the percent decrease in $\mathrm{A}_{550}$ increase. The resultant percent was then divided by $50 \%$ to normalize to units of SOD1 activity. These calculated units of SOD1 activity were then normalized for protein content by dividing by $\mathrm{mg}$ protein in the $50-\mu \mathrm{L}$ sample assayed. The protein content of the sample was determined by the method of Lowry et al. (20) using bovine serum albumin as a standard.

\section{Data quantitation and statistical analysis}

In order to ensure objectivity under blind conditions, all determinations or observations were performed by two observers for each experiment on control and experimental sections at the same time on the same day.
For quantitative analysis of SOD1 immunoreactivity in the skin, 15 sections per animal were randomly selected within the corresponding levels of the skin. At a magnification of 25-50X, the regions were outlined on the monitor and their areas were measured. All SOD1 immunoreactive structures taken from the epidermis and dermis were documented with an Axiophot light microscope (Carl Zeiss, Forschen, Germany) connected to a PC monitor via a CCD camera. Video images were digitized into an array of $512 \times 512$ pixels corresponding to a tissue area of $140 \times 140 \mu \mathrm{m}$ (40X primary magnification). To evaluate the SOD1 immunoreactive structures, the SOD1 immunolabeled structures were selected by the imageJ software by interactively determining each cell limit.

Each pixel resolution was of 256 gray levels. The intensity of SOD1 immunoreactivity was evaluated by means of a relative optical density (ROD) value. ROD was obtained after transformation of mean gray values into ROD using the formula: ROD = $\log$ (256/mean gray). The values of background staining were obtained and subtracted from the ROD values of all immunoreactive structures before statistical processing. ROD values are reported as ROD units. Also, the results of the Western blot study were scanned and an ROD value was obtained using the Scion Image software (Scion Corp., Frederick, MD, USA).

Inter-animal differences in each group and inter-experimental differences were not statistically significant. The values reported here are the means of experiments performed for each skin area. Differences among the means were analyzed statistically by oneway analysis of variance followed by the Duncan new multiple range method or Newman-Keuls test to elucidate the changes in SOD1 activity and protein levels in the PM extract-treated group compared to the control group or to characterize the dose-dependent changes of SOD1 activity and pro- 
tein levels. $\mathrm{P}<0.05$ was considered to be significant.

\section{Results}

\section{SOD1 immunoreactivity}

In the control group, weak SOD1 immunoreactivity was detected in the epidermis and dermis (Figure 1A). In the group treated with distilled water after UVB irradiation, SOD1 immunoreactivity was significantly decreased in the epidermis and dermis (Figures 1B and 2). In this group, SOD1 immunoreactivity almost disappeared in the skin. However, in the group treated with the PM extract after UVB irradiation, SOD1 immunoreactivity was significantly increased compared to control and to the group treated with distilled water after UVB irradiation (Figures $1 \mathrm{C}-\mathrm{E}$ and 2). In the 1\% PM extracttreated group, SOD1 immunoreactivity was markedly increased in the epidermis, while SOD1 immunoreactivity in the dermis was slightly increased (Figures $1 \mathrm{C}$ and 2). In the 2 and 4\% PM extract-treated groups, SOD1 immunoreactivity was increased in the epidermis as well as in the dermis (Figures 1D and 2). In the 8 and 16\% PM extract-treated groups, SOD1 immunoreactivity was significantly increased in both the epidermis and dermis (Figures 1E and 2).

\section{SOD1 protein levels}

In the group treated with distilled water after UVB irradiation, SOD1 protein levels were significantly reduced by $70 \%$ compared to the control group (Figure 3). However, in the PM extract-treated groups, SOD1 protein levels were dose-dependently increased compared to the distilled watertreated group (Figure 3). In the 1\% PM extract-treated group, SOD1 protein levels were increased by $41 \%$ vs the control group. In the 2 and 4\% PM extract-treated groups, SOD1 protein levels were 52 and $64 \%$ of
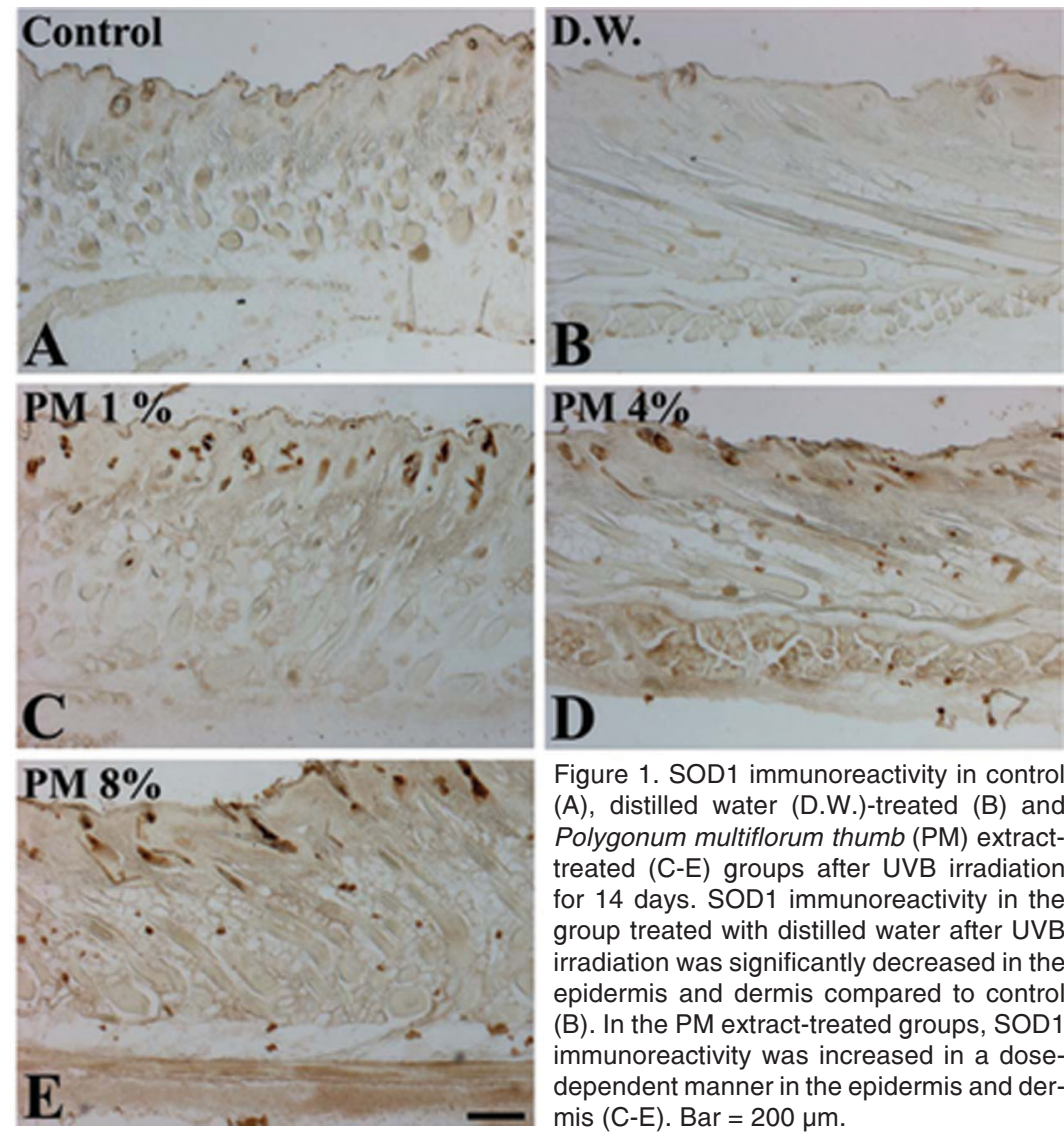

Figure 1. SOD1 immunoreactivity in control (A), distilled water (D.W.)-treated (B) and Polygonum multiflorum thumb (PM) extracttreated (C-E) groups after UVB irradiation for 14 days. SOD1 immunoreactivity in the group treated with distilled water after UVB irradiation was significantly decreased in the epidermis and dermis compared to control (B). In the PM extract-treated groups, SOD1 immunoreactivity was increased in a dosedependent manner in the epidermis and dermis (C-E). Bar $=200 \mu \mathrm{m}$.

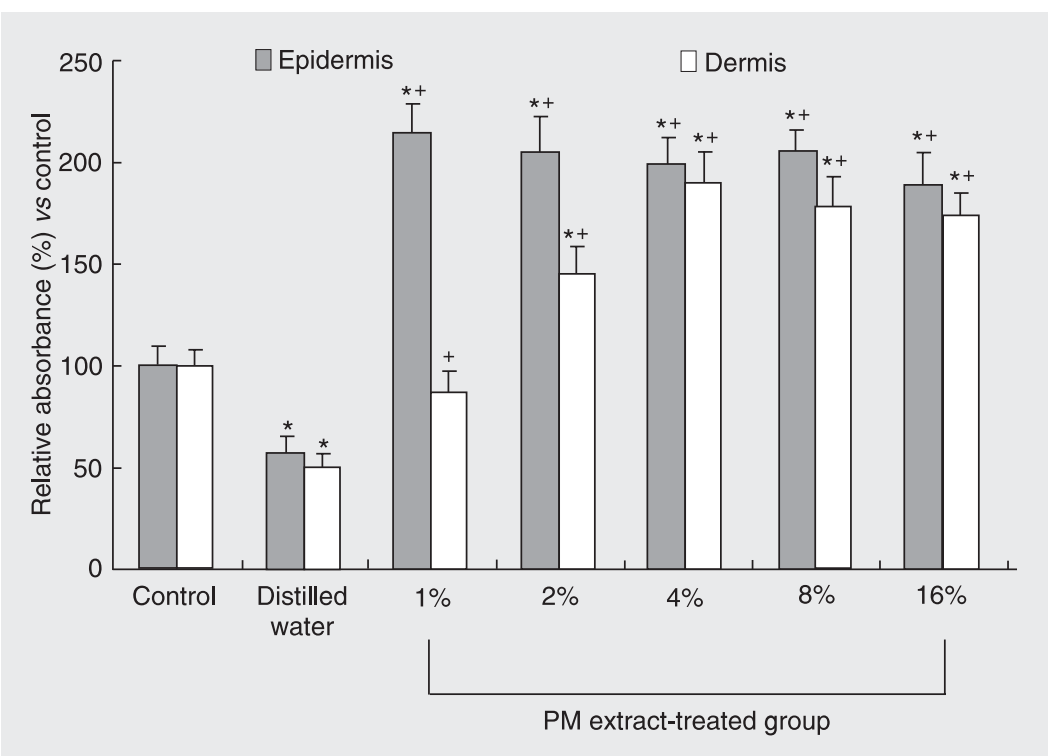

Figure 2. Relative absorbance of $\mathrm{Cu}, \mathrm{Zn}$-superoxide dismutase immunoreactivity in the epidermis and dermis of control $(\mathrm{N}=7)$, distilled water-treated $(\mathrm{N}=10)$ and Polygonum multiflorum thumb (PM) extract-treated groups $(n=10)$ after UVB irradiation for 14 days. The quantitative data obtained using image analysis were consistent with the immunohistochemical data. ${ }^{*} P<0.05$ compared to the control group; ${ }^{+} P<0.05$ compared to the distilled water-treated group (one-way ANOVA). Data are reported as means \pm SD. 


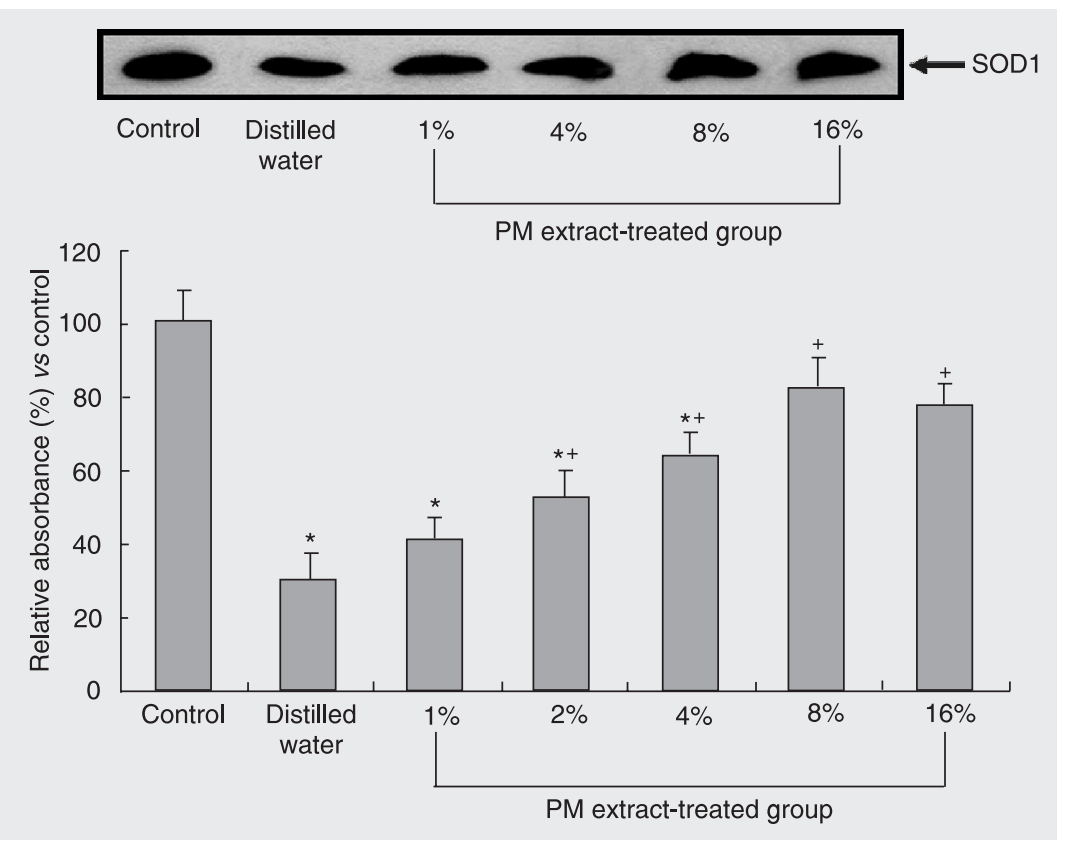

Figure 3. Top: Western blot analysis of SOD1. Bottom: Cu,Zn-superoxide dismutase (SOD1) protein levels in the skin of control $(\mathrm{N}=7)$, distilled water-treated $(\mathrm{N}=10)$ and Polygonum multiflorum thumb (PM) extract-treated groups $(\mathrm{N}=10)$ after UVB irradiation for 14 days. SOD1 protein levels of the distilled water-treated group were reduced compared to control. However, in the PM extract-treated groups, SOD1 protein levels were dose-dependently increased compared to the distilled water-treated group. ${ }^{*} \mathrm{P}<0.05$ compared to control; ${ }^{+} \mathrm{P}$ $<0.05$ compared to the distilled water-treated group (one-way ANOVA). Data are reported as means $\pm \mathrm{SD}$.

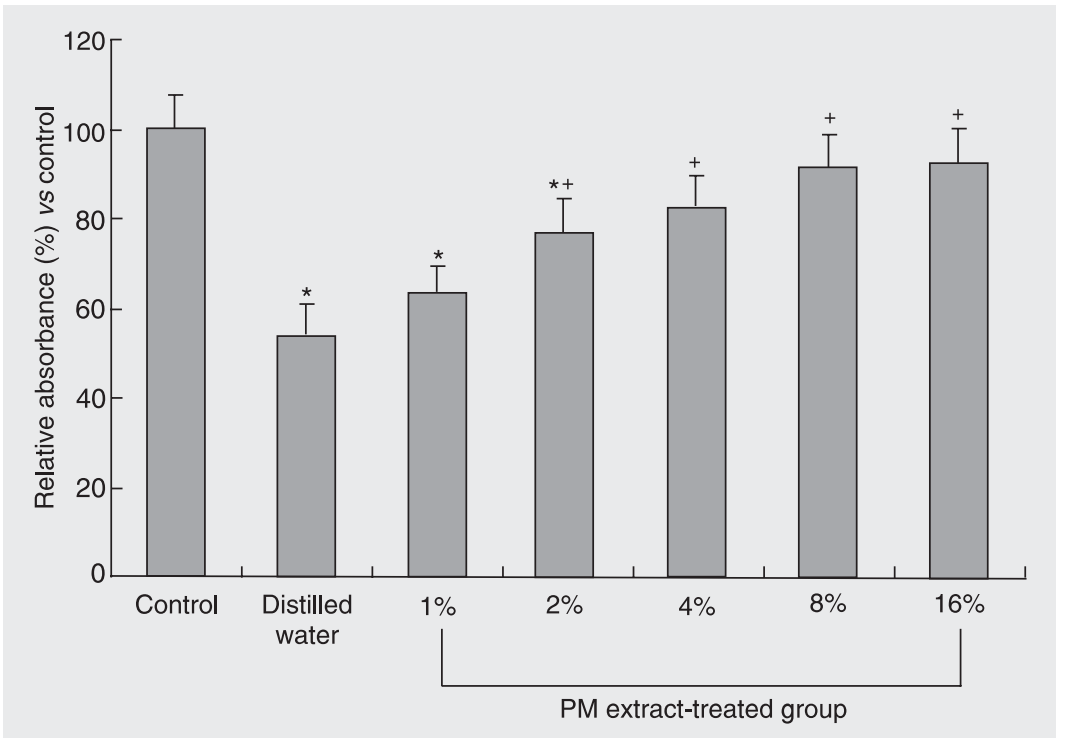

Figure 4. Relative Cu,Zn-superoxide dismutase (SOD1) specific activity in the skin of control $(\mathrm{N}=7)$, distilled water-treated $(\mathrm{N}=10)$ and Polygonum multiflorum thumb (PM) extract-treated groups $(\mathrm{N}=10)$ after UVB irradiation. SOD1 activity was significantly reduced in the distilled water-treated group, whereas it reached $90 \%$ of the control group levels in the $16 \%$ PM extract-treated groups. ${ }^{*} \mathrm{P}<0.05$ compared to control; ${ }^{+} \mathrm{P}<0.05$ compared to the distilled water-treated group (one-way ANOVA). Data are reported as means \pm SD. those in the control group. SOD1 protein levels in the 8 and 16\% PM extract-treated groups increased to 83 and $78 \%$ of control levels, respectively.

\section{SOD1 activity}

Skin SOD1 activity was reflected by Western blot data (not shown) in each experimental group (Figure 4). In the group treated with distilled water after UVB irradiation, SOD1 activity was significantly reduced to $53 \%$ of the activity of the control group. In the 1\% PM extract-treated group, SOD1 activity was $63 \%$ of that in the control group. In the 2 and 4\% PM extract-treated groups, SOD1 activity was 76 and $82 \%$ of the control group, respectively. In addition, in the 8 and $16 \%$ PM extract-treated groups, SOD1 activity was 91 and $92 \%$ of the control group, respectively.

\section{Discussion}

Antioxidants play a crucial role in ameliorating or indeed preventing photobiologic damage (phototoxicity, photoaging and cancers) in vivo $(21,22)$. It has been reported that PM extracts promote cellular antioxidant activity and increase the potency of SOD1 (14). A previous study reported that pretreatment with a PM extract produced a dose-dependent protection against myocardial ischemia-reperfusion injury and had the ability to sustain glutathione antioxidant status under conditions of ischemia/reperfusion-induced oxidative stress (13).

It has been reported that SOD1 activity is significantly suppressed by single-dose UVB irradiation (23), whereas it is induced by repeated exposure to UVB in response to chronic photo-oxidative stress (24). However, continual cumulative stress may overwhelm the capacity of this system, with SOD1 activity being significantly decreased in the skin (24). In the present study, chronic UVB irradiation of the skin induced a significant 
reduction in SOD1 immunoreactivity, its protein content and activity compared to control. This result suggests that endogenous SOD1 is utilized to neutralize UVBinduced oxygen free radicals. UVB-induced modifications include changes in proteins involved in cell cycle activity, cellular repair, proliferation, and apoptosis $(6,9,10)$. UVB irradiation produces an increase in reactive oxygen species such as superoxide ion and hydrogen peroxide. This apparent UVB-mediated increase in oxidative stress is further supported by a significant increase in muscle/skin thiobarbituric acid-like reactive species $(25,26)$. These radicals increase lipid peroxide levels in the skin, which reach a minimum 2-3 days after irradiation, and then gradually return to baseline. Hence, in cases of acute irradiation, SOD1 and its activities are sharply reduced $(27,28)$.

In the present study, topical administration of PM extracts to the mouse dorsal skin after UVB irradiation sustained SOD1 immunoreactivity, its protein content and activity against UVB irradiation-induced stress. These parameters were significantly reduced in the skin of the distilled water-treated group, whereas they were dose-dependently increased in the PM extract-treated group. The SOD1 protein levels and activities of the groups treated with 8 and 16\% PM extract after UVB irradiation recovered to $80-90 \%$ of control levels. These results indicate that topical application of PM extracts strongly inhibits the oxidative stress induced by UVB irradiation.

Chronic UVB irradiation of the skin reduces SOD1 immunoreactivity, protein content and activity. However, topical administration of PM extracts after UVB irradiation directly or indirectly sustains endogenous SOD1 immunoreactivity, activity and protein levels. These results suggest that PM extract may have an anti-photoaging effect against UVB irradiation.

\section{Acknowledgments}

The authors would like to thank Mr. Suek Han, Mr. Seung Uk Lee and Ms. Hyun Sook Kim from Hallym University for technical assistance.

\section{References}

1. Araki K, Nagano T, Ueda M, Washio F, Watanabe S, Yamaguchi N, et al. Incidence of skin cancers and precancerous lesions in Japanese - risk factors and prevention. J Epidemiol 1999; 9: S14-S21.

2. Maglio DH, Paz ML, Ferrari A, Weill FS, Czerniczyniec A, Leoni J, et al. Skin damage and mitochondrial dysfunction after acute ultraviolet B irradiation: relationship with nitric oxide production. Photodermatol Photoimmunol Photomed 2005; 21: 311-317.

3. Wang CB, Ding BX, Guo SB, Wang YZ, Han YT, Wang YJ. Protective effect of polypeptide from Chlamys farreri on mitochondria in human dermal fibroblasts irradiated by ultraviolet B. Acta Pharmacol Sin 2003; 24: 692-696.

4. Granstein RD, Matsui MS. UV radiation-induced immunosuppression and skin cancer. Cutis 2004; 74: 4-9.

5. Saurat JH. Skin, sun, and vitamin A: from aging to cancer. J Dermatol 2001; 28: 595-598.

6. Ambach W, Blumthaler M. Biological effectiveness of solar UV radiation in humans. Experientia 1993; 49: 747-753.

7. Babu V, Misra RB, Joshi PC. Ultraviolet-B effects on ocular tissues. Biochem Biophys Res Commun 1995; 210: 417-423.

8. Cleaver JE, Crowley E. UV damage, DNA repair and skin carcinogenesis. Front Biosci 2002; 7: D1024-D1043.
9. de Gruijl FR, van Kranen HJ, Mullenders LH. UV-induced DNA damage, repair, mutations and oncogenic pathways in skin cancer. J Photochem Photobiol B 2001; 63: 19-27.

10. Brenneisen $P$, Sies $H$, Scharffetter-Kochanek K. Ultraviolet-B irradiation and matrix metalloproteinases: from induction via signaling to initial events. Ann NY Acad Sci 2002; 973: 31-43.

11. Cohen D, DeLeo VA. Ultraviolet radiation-induced phospholipase A2 activation occurs in mammalian cell membrane preparations. Photochem Photobiol 1993; 57: 383-390.

12. Jeon SE, Choi-Kwon S, Park KA, Lee HJ, Park MS, Lee JH, et al. Dietary supplementation of $(+)$-catechin protects against UVB-induced skin damage by modulating antioxidant enzyme activities. Photodermatol Photoimmunol Photomed 2003; 19: 235-241.

13. Yim TK, Wu WK, Mak DH, Ko KM. Myocardial protective effect of an anthraquinone-containing extract of Polygonum multiflorum ex vivo. Planta Med 1998; 64: 607-611.

14. Hong CY, Lo YC, Tan FC, Wei YH, Chen CF. Astragalus membranaceus and Polygonum multiflorum protect rat heart mitochondria against lipid peroxidation. Am J Chin Med 1994; 22: 63-70.

15. NIH. Guide for the care and use of laboratory animals. Bethesda: NIH Publication No. 85-23 (revised 1996); 1985. 
16. Lin LC, Nalawade SM, Mulabagal V, Yeh MS, Tsay HS. Micropropagation of Polygonum multiflorum THUNB and quantitative analysis of the anthraquinones emodin and physcion formed in in vitro propagated shoots and plants. Biol Pharm Bull 2003; 26: 1467-1471.

17. Athar M, An KP, Tang X, Morel KD, Kim AL, Kopelovich L, et al. Photoprotective effects of sulindac against ultraviolet B-induced phototoxicity in the skin of $\mathrm{SKH}-1$ hairless mice. Toxicol Appl Pharmacol 2004; 195: 370-378.

18. Hwang IK, Eum WS, Yoo KY, Cho JH, Kim DW, Choi SH, et al. Copper chaperone for $\mathrm{Cu}, \mathrm{Zn}$-SOD supplement potentiates the $\mathrm{Cu}, \mathrm{Zn}$-SOD function of neuroprotective effects against ischemic neuronal damage in the gerbil hippocampus. Free Radic Biol Med 2005; 39: 392-402.

19. Leccia MT, Yaar M, Allen N, Gleason M, Gilchrest BA. Solar simulated irradiation modulates gene expression and activity of antioxidant enzymes in cultured human dermal fibroblasts. Exp Dermatol 2001; 10: 272-279.

20. Lowry OH, Rosebrough N, Farr A, Randall R. Protein measurement with the Folin phenol reagent. J Biol Chem 1951; 193: 265-275.

21. Farris PK. Topical vitamin C: a useful agent for treating photoaging and other dermatologic conditions. Dermatol Surg 2005; 31: 814817.

22. Kondo S, Mamada A, Yamaguchi J, Fukuro S. Protective effect of dlalpha-tocopherol on the cytotoxicity of ultraviolet B against human skin fibroblasts in vitro. Photodermatol Photoimmunol Photomed
1990; 7: 173-177

23. Pence BC, Naylor MF. Effects of single-dose ultraviolet radiation on skin superoxide dismutase, catalase, and xanthine oxidase in hairless mice. J Invest Dermatol 1990; 95: 213-216.

24. Okada K, Takahashi Y, Ohnishi K, Ishikawa O, Miyachi Y. Timedependent effect of chronic UV irradiation on superoxide dismutase and catalase activity in hairless mice skin. J Dermatol Sci 1994; 8: 183-186.

25. Romeu M, Mulero M, Giralt M, Folch J, Nogues MR, Torres A, et al. Parameters related to oxygen free radicals in erythrocytes, plasma and epidermis of the hairless rat. Life Sci 2002; 71: 1739-1749.

26. Savoure N, Maudet M, Nicol M, Pelissier MA, Albrecht R, Briand G, et al. Modulation of ultraviolet light-induced oxidative stress in mice skin related to dietary vitamin $\mathrm{A}$ and selenium intake. Int $J$ Vitam Nutr Res 1996; 66: 306-315.

27. Aricioglu A, Bozkurt M, Balabanli B, Kilinc M, Nazaroglu NK, Turkozkan N. Changes in zinc levels and superoxide dismutase activities in the skin of acute, ultraviolet-B-irradiated mice after treatment with Ginkgo biloba extract. Biol Trace Elem Res 2001; 80: 175179.

28. lizawa O, Kato T, Tagami H, Akamatsu H, Niwa Y. Long-term followup study of changes in lipid peroxide levels and the activity of superoxide dismutase, catalase and glutathione peroxidase in mouse skin after acute and chronic UV irradiation. Arch Dermato Res 1994; 286: 47-52. 